\title{
AUGE, CAÍDA Y CONTINUIDAD DE UNA ÉLITE DE GOBIERNO. NOMBRAMIENTOS DE NUEVA PLANTA EN LOS CONSEJOS DE LA MONARQUÍA BORBÓNICA (1713-1720)
}

\author{
Rise, Fall and Continuity of Government Elite. \\ The Appointments of New Plant in the Councils \\ of the Bourbon Monarchy (1713-1720)
}

\author{
Francisco PRECIOSO IZQUIERDO ${ }^{1}$ \\ Universidad de Murcia \\ fpi13824@um.es
}

Fecha de recepción: 19/11/2014

Fecha de aceptación definitiva: 25/03/2015

RESUMEN: La serie de reformas institucionales planteadas en el reinado de Felipe V tiene en los decretos de Nueva Planta de 1713-1714 uno de sus principales hitos. La nueva organización de los consejos representará el punto álgido del reformismo filipino liderado por el equipo regalista de Ursinos y Orry. Secundados por

1. Esta contribución ha sido realizada gracias a la concesión de una beca pre-doctoral por la Fundación Séneca, Agencia de Ciencia y Tecnología de la Región de Murcia (15520/FPI/10). Así mismo, forma parte de los proyectos de investigación: «Nobilitas II- Estudios y base documental de la nobleza del Reino de Murcia, siglos XV-XIX. Segunda fase: análisis comparativos», financiado por la Fundación Séneca, Agencia de Ciencia y Tecnología de la Región de Murcia (15300/PHC/10) y «Familias e individuos: Patrones de modernidad y cambio social (siglos XVI-XXI)", financiado por el Ministerio de Economía y Competitividad (HAR2013-48901-C6-1-R). Abreviaturas Archivos y bibliotecas citadas: AAE (Archive des Affaires Étrangères de Paris), AGS (Archivo General de Simancas), AHN (Archivo Histórico Nacional), AUSA (Archivo Universidad de Salamanca), BNE (Biblioteca Nacional de España), RAH (Real Academia de la Historia). 
el fiscal general Melchor Macanaz, tendrán que hacer frente a la reacción generada entre quienes se opondrán a la novedad desde dentro, lo que se intentará mediante el nombramiento de personal cercano a las autoridades en el gobierno, en especial, próximos al fiscal murciano. Nuestro objetivo será el análisis relacional del conjunto de hombres seleccionados para ocupar las reformadas instituciones, proponiendo una interpretación que parta de las relaciones de patronazgo administrativo tejidas en torno a Macanaz. Finalmente, nos interesaremos por las trayectorias de los favorecidos tras la contra-reforma de 1715 .

Palabras Clave: Siglo XVIII; nueva planta de los consejos; patronazgo administrativo; Felipe V; Melchor Macanaz.

ABSTRACT: The decrees of institutional reform of 1713 and 1714 are a milestone in the administrative reforms proposed in the reign of Felipe V. The new organization of councils was to be seen as a victory of reformism proposed by the regalist in power. However, opposition from many administrators forced the authorities to nominate new places with people close to the government. Our aim in this paper is the relational analysis of the men selected to occupy the reformed institutions. We propose an interpretation that is based on administrative patronage relationships around Macanaz. Finally, we are interested in the trajectories of those favored after the counter-reform of 1715 .

Key words: $18^{\text {th }}$ Century; New plant of the councils; Administrative patronage; Felipe V; Melchor Macanaz.

\section{INTRODUCCIÓN. REFORMAS, INSTITUCIONES Y PATRONAZGO}

En la obra de reformas emprendidas durante el reinado de Felipe V, uno de los objetos que mayor atención ha despertado en la historiografía ha sido el relacionado con la renovación institucional de la monarquía. El interés por el funcionamiento y dinámica de los órganos de la administración y gobierno tras el advenimiento de la nueva dinastía, coincide con un periodo de auge de los estudios institucionales planteados desde paradigmas diferentes a los tradicionales. Las nuevas miradas de la renovada historia de la administración y el poder, han permitido profundizar en los aspectos sociales y relacionales de las otrora descarnadas instituciones, poniendo de relieve la trascendencia del colectivo humano que daba forma, cuerpo y que solía responder a los fines perseguidos a través de ellas.

Este impulso historiográfico ha beneficiado el seguimiento de algunas de las reformas más significativas llevadas a cabo por Felipe V, lo que a su vez, ha contribuido a sacar a la luz un buen número de variables para su análisis. Se ha destacado, en primer lugar, el grado de coherencia de la administración filipina con la propia configuración seguida por la monarquía tras la derogación de los fueros territoriales de la corona de Aragón; los instrumentos gubernativos se adaptarían 
así al nuevo orden centralizado y homogeneizado de la monarquía española ${ }^{2}$. Otro de los juicios constantes de la historiografía es aquel que vincula los cambios en el aparato institucional con el tránsito del sistema judicialista a favor del ejecutivo, proceso que tendría como objetivo la búsqueda de una forma de gobierno más ágil que facilitara al monarca una resuelta toma de decisión ${ }^{3}$. Tal modificación vendría representada por la consolidación de las secretarías del Despacho y la decadencia de los consejos, por lo que su coexistencia final, no sería más que la constatación de la resistencia de parte del "establishment» político, y en última instancia, la manifestación de las limitaciones propias del reformismo borbónico de primera hora ${ }^{4}$.

Los cambios referidos tendrán además su corolario social, pues supondrán la elevación de nuevas familias, grupos e individuos procedentes en su mayoría de los estratos no privilegiados de la sociedad, pequeña y baja nobleza y oligarquía urbana de la periferia 5 . Una élite de gobierno con la que el rey ganaba en autonomía frente a los poderosos del reino, aquellos que habían logrado monopolizar los resortes del poder en reinados anteriores ${ }^{6}$, se veían ahora comprometidos a ceder y compartir protagonismo con la élite emergente .

La creciente atención y el estudio de las reformas institucionales de Felipe V, ha vuelto a poner sobre la mesa la valoración del componente ideológico de los cambios. Algunos autores han apuntado en la dirección de «un plan sistemático de conquista del Estado por el soberano" ${ }^{8}$, objetivo que trataría de devolver al rey al centro mismo del sistema. Visto de esta manera, quiebra felizmente la tradicional consideración de la Francia de Luis XIV como espejo único de las reformas

2. Fernández Albaladejo, Pablo. Fragmentos de monarquía: Trabajos de Historia política. Madrid: Alianza, 1992, pp. 353-454.

3. LÓPEZ-CORDÓN CORTEZO, María Victoria. "Instauración dinástica y reformismo administrativo: la implantación del sistema ministerial». Manuscrits, 2000, 18, pp. 93-111; misma autora, "La Nueva Planta del Estado: consejos y secretarías». En MORAles MoyA, Antonio (ed.). 1714. Cataluña en la España del siglo XVIII. Madrid: Cátedra, 2014, pp. 113-156; Escudero López, José Antonio. «La reconstrucción de la administración central en el siglo XVIII". En VV. AA. La época de los primeros Borbones. XXIX/I. Madrid: Espasa-Calpe, 1987, pp. 79-175.

4. Castellano Castellano, Juan Luis. Sociedad, Administración y poder en la España del Antiguo Régimen. Granada, 1996, pp. 28-34 y 60-71.

5. Molas Ribalta, Pere. Los gobernantes de la España Moderna. Madrid: Actas, 2008, pp. 224225; Imizcoz Beunza, José María y Guerrero Elecalde, Rafael. «Familias en la Monarquía. La política familiar de las elites vascas y navarras en el imperio de los Borbones». En Imizcoz Beunza, José María (ed.). Casa, familia y sociedad (País Vasco, España y América, siglos XV-XIX). Bilbao: Universidad del País Vasco, 2004, pp. 178-179.

6. Kamen, Henry. La Guerra de Sucesión. Barcelona: Grijalbo, 1974, pp. 99-135.

7. Dedieu, Jean-Pierre. "Dinastía y élites de poder en el reinado de Felipe V». En FERnándEZ Albaladejo, Pablo (ed.). Los Borbones. Dinastía y memoria de nación en la España del siglo XVIII. Madrid: Marcial Pons, 2002, pp. 381-399

8. Dedieu, Jean-Pierre. "La Nueva Planta en su contexto. Las reformas del aparato del Estado en el reinado de Felipe V». Manuscrits, 2000, 18, p. 137. 
adoptadas en España por su nieto; ambas monarquías compartirían así una misma cultura política de orientación absolutista que les llevaría a emplear soluciones similares sobre realidades no tan diferentes?.

Las conclusiones anteriores han permitido avanzar en la complejidad y variedad de factores a la hora de evaluar el conjunto de medidas puestas en marcha en materia institucional bajo el reinado de Felipe V. La interpretación no será ya tan lineal ni simple como la mera ejecución de un plan diseñado ex ante, unidireccional y finalista aplicado sin mayores reservas; si bien es cierto que las reformas planteadas y ejecutadas definen una tendencia hacía la concentración de recursos en manos del rey, el fortalecimiento de la vía reservada y el protagonismo social de las oligarquías urbanas y burócratas ennoblecidos, no es menos que tales cambios y sobre todo su ritmo afectarán de una manera desigual a lo largo del reinado, dependiendo -como afirma Delgado Barrado- de las "reformas», los "reformismos» y en definitiva, los diferentes gobiernos encargados de llevarlas a cabo $^{10}$. Esto último hace girar nuestro análisis hacia la centralidad que ocuparán las personas y grupos cercanos al rey. Serán aquellos prebostes del gobierno y la administración, cabezas visibles de grupúsculos o partidos cortesanos, quienes tendrán la capacidad suficiente para hacer inclinar a un lado u otro el sentido de las reformas no solo en función de proyectos o motivaciones ideológicas, como también, de sus propios intereses y circunstancias personales ${ }^{11}$.

El interés por el poder, como elemento dinamizador y estructurador de la realidad política, encontrará perfecto acomodo en los sistemas administrativos de las monarquías modernas, construidos sobre la base de extensas redes de relaciones donde el vínculo personal era determinante ${ }^{12}$. En este sentido, la incorporación de factores como el clientelismo y patronazgo ayudan a completar el nivel de descripción ligado a categorías comúnmente empleadas en los análisis sociales de la administración, como la discutida cuestión colegial versus manteísta o los letrados y abogados, etiquetas que por sí solas apenas son capaces de explicar la

9. DuBET, Anne. "¿La importación de un modelo francés? Acerca de algunas reformas de la administración española a principios del siglo XVIII". Revista de Historia Moderna, 2007, 25, pp. 207-233.

2008: 19-36; DuBET Anne y Ruíz IBÁÑEZ, José Javier. Las monarquías española y francesa (siglos XVI-XVIII). ¿Dos modelos políticos? Madrid: Casa de Velázquez, 2010, pp. 213-222.

10. Delgado Barrado, José Miguel. Aquiles y Teseos. Bosquejos del reformismo borbónico. Granada: Universidad de Granada, 2007, pp. 9-11.

11. GIL Pujol, Xavier. "Notas sobre el estudio del poder como nueva valoración de la historia política». Pedralbes. Revista de Historia Moderna, 1983, 3, pp. 61-88.

12. MARTínez Millán, José. "Las investigaciones sobre patronazgo y clientelismo en la Administración de la Monarquía Hispana durante la Edad Moderna». Studia Historica. Historia Moderna, 1996, 15, pp. 89-97. Los análisis de redes ligadas a la administración y gobierno están siendo objeto de una profunda actualización teórica y aplicación práctica. Vid. IMIZCOZ BEUNZA, José María y GuERRERO ELECALDE, Rafael. Familias en la (...). Op. cit., pp. 145-175. 
preponderancia de unas sobre otras si previamente no se tienen en cuenta claves como la dependencia y el patrocinio ${ }^{13}$.

La administración filipina conocerá uno de los momentos álgidos de reformismo institucional con la publicación de los decretos de Nueva Planta de los consejos en noviembre de 1713 y abril de 1714. Se trata de un paso más en la dirección de la monarquía absolutista, en la que todos los espacios de poder temporal debían quedar bajo la autoridad indiscutible del monarca ${ }^{14}$. Una reforma crucial con la que se favorecía además la privilegiada posición política de los ministros regalistas impulsores de la medida frente a la clase politica de consejeros y presidentes de consejos, críticos en su mayoría con la línea de reformas planteadas por aquellos ${ }^{15}$.

La Nueva Planta de los consejos ha merecido una atención desigual por parte de la historiografía, primando enfoques parciales por encima de perspectivas globales. Entre todas, destaca la contribución de Escudero López, quien ha analizado con exactitud los principales cambios orgánicos experimentados en el régimen polisinodial durante el bienio $1713-1715^{16}$. Junto a las modificaciones jurídicas, los aspectos sociales han sido estudiados casi siempre en función de tal o cual consejo. Este será el caso de los trabajos - plenamente actuales hoy- de la historiadora Janine Fayard sobre los miembros del consejo de Castilla y el intento de reforma emprendido por Macanaz ${ }^{17}$. El profesor Andújar Castillo también ha subrayado en su análisis sobre la evolución del consejo de Guerra, numerosas características del grupo de consejeros promocionados durante la vigencia de la Nueva Planta ${ }^{18}$. Desde diferentes ámbitos de investigación como el gobierno ${ }^{19}$, cargos institucionales $^{20}$,

13. Línea de trabajo de la que han resultado textos y aportaciones excelentes, entre otros: Dedieu, Jean-Pierre. «La muerte del letrado». En ARANDA PÉREZ, José Francisco (Coord). Letrados, juristas y burócratas en la España Moderna. Cuenca: Universidad de Castilla-La Mancha: 2005, pp. 479-511; CARABIAS TORRES, Ana María. "iLa muerte del letrado? Consideraciones sobre la tipología del oficial español en el siglo XVIII». En Dios DE Dios, Salustiano de y ToRIJANO, Eugenia (coords.). Cultura política y práctica del derecho. Juristas de Salamanca, siglos $X V-X X$. Salamanca: Universidad de Salamanca: 2012, pp. 143-238.

14. DEDIEU, Jean Pierre. «El aparato de gobierno de la monarquía española en el siglo XVIII". En PÉREZ SARRIÓN, Guillermo (Coord). Más Estado y más mercado: absolutismo y economía en la España del siglo XVIII. Madrid: Sílex, 2011, pp. 53-74.

15. Dedieu, Jean-Pierre. La Nueva Planta (...). Art. cit., pp. 118-122.

16. Escudero López, José Antonio. La reconstrucción de (...). Op. cit., pp. 103-111.

17. FAYARD, Janine. "La tentative de rêforme du Conseil de Castille sous le regne de Philippe V (1713-1715)". Mélanges de la Casa de Velázquez, 1966, 2, pp. 259-282; misma autora. Los miembros del Consejo de Castilla (1621-1746). Madrid: Siglo XXI, 1982, pp. 156-160.

18. Andújar Castillo, Francisco. Consejo y consejeros de Guerra en el siglo XVIII. Granada: Universidad de Granada, 1996, pp. 36-50.

19. Castellano Castellano, Juan Luis. Gobierno y poder (...). Op. cit., pp. 60-64.

20. Coronas GonZÁlez, Santos Manuel. Ilustración y Derecho. Los fiscales del Consejo de Castilla en el siglo XVIII. Madrid: Ministerio Administraciones Públicas, 1992, pp. 45-50. 
grupos de poder ${ }^{21}$ o biografías políticas ${ }^{22}$, otros tantos historiadores han ofrecido abundantes datos que nos han permitido conocer en mayor medida al colectivo que sirvió en las renovadas instituciones.

Nuestro objetivo se centra ahora en el análisis social de los nombramientos de la Nueva Planta de los consejos; por un lado, examinaremos qué personas ocuparon las novedades institucionales introducidas por los decretos de noviembre de 1713, por otro, analizaremos quiénes serán los nombrados a lo largo de 1714 con ocasión de los dos grandes movimientos de personal que se sucederán en los meses posteriores. Una labor en la que se empleará a fondo el fiscal murciano Melchor Macanaz, quien informará, propondrá y patrocinará a decenas de hombres, piezas básicas en la tarea de domesticación de las instituciones que se estaban reformando.

Junto al estudio de los efectos positivos del patrocinio desplegado por Macanaz, pronto se descubrirá una dimensión mucho más comprometedora; cesado el fiscal, la mayoría de sus favorecidos quedarán entonces señalados por un factótum políticamente incorrecto. No obstante, el lastre de haber servido en la administración tutelada por don Melchor, apenas impedirá a los promocionados reincorporarse a la carrera administrativa tras un oportuno alejamiento temporal. El examen de los memoriales elevados por éstos al rey en 1715, nos servirá para analizar la manera con la que muchos tratarán de desvincular su suerte de la del ministro caído, individualizando su caso para minimizar los efectos de un patronazgo incómodo en un tiempo nuevo.

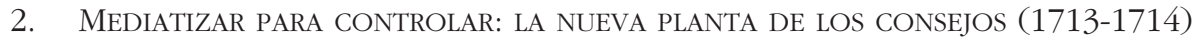

Iniciadas las conversaciones de paz con las potencias Aliadas, en la península, la guerra iba a continuar unos meses más hasta la toma de Cataluña y Baleares (1714-1715). Antes, el 10 de noviembre de 1713, tendrá lugar la publicación de una serie de decretos que darán nueva forma, organización y plantilla a los consejos de la monarquía. Todos, salvo el de Guerra e Inquisición (cuyas reformas habrían de esperar hasta abril y diciembre de $1714^{23}$ ), verán alteradas sus

21. Guerrero Elecalde, Rafael. Las élites vascas en el gobierno de la monarquía borbónica: redes sociales, carreras y hegemonía en el siglo XVIII (1700-1746). Tesis Doctoral. Universidad del País Vasco, 2012, pp. 113-129; Molas Ribalta, Pere. Los gobernantes de (...). Op. cit., pp. 232-236.

22. Martín Gaite, Carmen. Macanaz, otro paciente de la Inquisición. Barcelona: Destino, 1982, pp. 227-230; Castro, Concepción de. A la sombra de Felipe V. José Grimaldo, ministro responsable (1703-1726). Marcial Pons: Madrid, 2004, pp. 248-253.

23. Sobre la reforma del consejo de Inquisición, vid. EGIDo López, Teófanes. "Las reformas fracasadas. El significado de Macanaz. En Pérez Villanueva, Joaquín y Escandell Bonet, Bartolomé (dirs.). Historia de la Inquisición en España y América (vol. I.). Madrid: B.A.C., 1984, pp. 1234-1247; García-Hevia, José María. "Macanaz y su propuesta de reforma del Santo. Oficio de 1714». Revista de Inquisición. 1996, 5, pp. 218-327. 
estructuras y renovado su personal. Justificada la Nueva Planta en razones de economía y agilización administrativa, el "golpe de fuerza contra los consejos» pretenderá limitar la notable autonomía política de los mismos. Un margen de soberanía, como en el caso del consejo de Castilla ${ }^{24}$, que llegaba a escapar en ocasiones a los propósitos reales, asumiendo -en palabras de Dedieu- una función propia de "guardianes del equilibrio de poder ${ }^{25}$. La autonomía casi ilimitada será el motivo que -según Kamen- moverá a Felipe $\mathrm{V}$ a su reforma, sobre todo tras el disenso entre las autoridades del consejo y el nuevo rey, a cuenta del cambio en la ley de sucesión planteado en 1712 por el monarca ${ }^{26}$.

Fuera o no la actitud de parte del consejo de Castilla el detonante de los decretos de noviembre, la oportunidad de acometer unas reformas consideradas necesarias por el equipo regalista cercano entonces a Felipe V no iba a ser desaprovechada ${ }^{27}$. Imputada la paternidad de la Planta de 1713 al hacendista Jean Orry, parece innegable que en su formulación y puesta en práctica colaboró el jurista murciano Melchor Macanaz ${ }^{28}$. La respuesta es conocida: no se acabará con los consejos, antes bien, se lleva a cabo una profunda reorganización por la que quedan subordinados a la autoridad real; una auténtica inversión de fuerzas a favor del rey que se conseguirá cercenando la tradicional autonomía de los mismos, dotándolos de una nueva estructura que favorecerá un mayor control por parte del monarca. Con los consejos reducidos a órganos eminentemente técnicos e intervenidos, su protagonismo debía ir cediendo a favor de las secretarías del Despacho, instituciones potenciadas seguidamente por otro decreto de 30 de noviembre de 1714, con el que se terminaba de apuntalar el tipo de administración y gobierno pretendido por los reformistas en el poder, sobre la base -como afirma López-Cordón Cortezo- del sistema ministerial, especializado y de despacho directo con el monarca ${ }^{29}$.

Entre los cambios más sobresalientes de la Nueva Planta destaca la supresión de la presidencia o gobernación única de los consejos, cargo que ahora se divide

24. FAYARD, Janine. La tentative de (...). Art. cit., pp. 259-282.

25. Dedieu, Jean-Pierre. La Nueva Planta (...). Art. cit., pp. 118-119.

26. Kamen, Henry. Felipe V. El rey que reinó dos veces. Madrid: Temas de Hoy, 2010, pp. 106-107.

27. Baste recordar la Explicación Jurídica sobre las atribuciones del consejo de Castilla, elaborada parcialmente por Macanaz junto a Salazar y Castro (1709), para conocer la negativa opinión de los reformistas sobre la ilimitada soberanía y autoridad que el consejo se atribuía en sus prerrogativas. Vid. García-BADElls ARIAS, Luis María. «Felipe V, la Nobleza Española y el Consejo de Castilla. La Explicación jurídica e histórica de la consulta que hizo el Real Consejo de Castilla, atribuida a Macanaz». Cuadernos de Historia del Derecho, 2005, 12, pp. 125-149.

28. El propio Macanaz se referirá años después a la reforma de los consejos en un tono sorprendentemente crítico, afirmando que «desde 1701 acá, Mr. Orri hizo cuanto pudo para ponerlo en el confuso desorden de los Parlamentos de Francia, multiplicando Presidentes y ministros", Semanario Erudito. Tomo VII, 1788, p. 270. Sobre la reforma del consejo de Castilla, FAYARD, Janine. La tentative de (...). Art. cit., pp. 259-282.

29. López-Cordón CORTEzo, María Victoria. Instauración dinástica y (...). Art. cit., pp. 101-105. 
en varías titularidades con el fin -recuerda Escudero López- de restar importancia a uno de los empleos de mayor significación política de la monarquía ${ }^{30}$. El número de consejeros, por su parte, se verá incrementado proporcionalmente en la mayoría de consejos. La cara en la nueva organización será para los fiscales generales, quienes verán reforzado su papel político con la asistencia de cargos creados ex novo, como los abogados generales y los sustitutos del fiscal, así como la labor desempeñada por los secretarios «en jefe ${ }^{31}$ ». Presidentes, fiscales, consejeros, abogados generales y secretarios que intervendrán en las diferentes salas de los consejos, también reorganizadas y definidas sus competencias con mayor claridad ${ }^{32}$. Otra de las medidas más controvertidas, la desaparición de la Cámara de Castilla -cuyas competencias pasaban a la sala de Gobierno del consejo-, supondrá un no disimulado aldabonazo contra la tradicional influencia de los Colegios Mayores en la administración central ${ }^{33}$.

Tales cambios orgánicos llevarán parejo el nombramiento del personal necesario para el funcionamiento de la Nueva Planta. En un primer momento, la composición de los consejos parece definirse por una aparente continuidad, ya que la mayoría de los cargos existentes serán confirmados, otros son recolocados, mientras se busca entre la abogacía y la administración local, al resto de administradores para completar el cuadro social de las reformadas instituciones. Entre estos últimos, muchos podrán acreditar cierta cercanía o proximidad con alguno de los dirigentes del momento, en especial, con Melchor Macanaz y el propio Orry ${ }^{34}$. El caso del consejo de Castilla vuelve a ser paradigmático; cuatro de los cinco presidentes serán designados entre consejeros que ya lo eran antes de noviembre de 1713 (Juan Antonio Torres, el Marqués de Andía, García Pérez Araciel y Miguel Francisco Guerra) ${ }^{35}$, y solo uno, el primer presidente, Francisco Rodríguez Mendarozqueta, obispo de Sigüenza y comisario general de Cruzada, será designado ad hoc $^{36}$. Misma tendencia continuista se observa en la composición del cuerpo de consejeros, ya que de los veinticuatro que señala el decreto, dieciséis procederán

30. Escudero López, José Antonio. La reconstrucción de (...). Op. cit., pp.104-105.

31. Especialmente estudiado en el consejo de Castilla, en la Nueva Planta se redefinen las atribuciones tradicionales del fiscal, pasando a ejercer una función de control y manejo de la actividad diaria del consejo, vid. Coronas González, Santos Manuel, Ilustración y derecho (...). Op. cit., pp. 45-48. Para el resto de cargos subalternos, Escudero López, José Antonio, La reconstrucción de (...). Op. cit., pp. 104-109.

32. Cabrera Bosch, María Isabel. El consejo real de Castilla y la ley. Madrid: CSIC, 1993, PP. 5-9.

33. La influencia colegial en la alta administración, basada en el control de la propia Cámara, sería denunciada tempranamente por los círculos manteístas en un memorial a Felipe V en 1701. Vid. SAlas Balust, Luis. Reales reformas de los antiguos Colegios de Salamanca anteriores a las del reinado de Carlos III (1628-1770). Estudios y Documentos, 1956, 10, pp. 46-51.

34. BNE, Ms.11. 263, ff. 1r-2v.

35. Guerrero Elecalde, Rafael, Las élites vascas (...). Op. cit., pp. 115-117.

36. Colaborador habitual de José Grimaldo, Castro, Concepción de. A la sombra (...). Op. cit., p. 251. 
de la planta anterior ${ }^{37}$. Tanto unos como otros se repartirán entre las cinco salas en las que quedaba organizado el reformado consejo (consejo Pleno y salas de Gobierno, Justicia, Provincia y Criminal) ${ }^{38}$.

Más parcial resulta el perfil de aquellos que son nombrados para ocupar las novedades institucionales de la Nueva Planta, sobre todo, los cargos de fiscal y abogados generales. Respecto al primero, como ya dijimos, es reservado al mismo Melchor Macanaz, en quien recaerá la labor de fiscalización y promoción de personal en el resto de consejos $^{39}$. Los abogados generales que lo flanquean bien pueden ser considerados por entero favorecidos suyos; se trata del abogado almanseño Luis Sánchez Ulloa y el aragonés José Rodrigo Villalpando. Sánchez Ulloa, hombre muy cercano a don Melchor, mantendrá una larga trayectoria en común desde sus años de estudio en las universidades de Valencia y Salamanca ${ }^{40}$. Posteriormente Macanaz contará con él durante su polémico empleo como juez de confiscaciones en el reino de Valencia ${ }^{41}$, nombrándolo en la planta de 1713, segundo abogado general del consejo de Castilla. A José Rodrigo, a quien conocía de su primera estancia en Aragón en 1706, lo elevaba desde la fiscalía de la audiencia aragonesa a la primera abogacía de la institución ${ }^{42}$. Mientras, las cuatro secretarías del consejo irán destinadas a administradores que, o bien desempeñaban ya sus funciones en la extinta Cámara de Castilla, o bien se encontraban previamente relacionados con la propia administración central, como Lorenzo de Vivanco Angulo ${ }^{43}$, José Saénz de Vitoria ${ }^{44}$, Francisco de Quincoces ${ }^{45}$ y Juan Milán de Aragón ${ }^{46}$.

37. FAYARD, Janine. La tentative de (...). Art. cit., p. 282.

38. Cabrera Bosch, María Isabel. El consejo real (...). Op. cit., pp. 7-8.

39. En el decreto de nombramiento de Macanaz se especificará esta facultad: «si huviere quejas contra ministros inferiores por su mala conducta u otros delitos, procurareis por vuestra representación que el Consejo informe de ellos, proponiéndome (en el caso de suspensión de sus empleos) otros que en el interin los sirvan", Coronas González, Santos Manuel, Ilustración y derecho (...). op. cit., pp. 265-266.

40. Ambos comenzarán su formación en la Facultad de Derecho de la Universidad de Valencia entre 1687 y 1690, continuándola en la Universidad de Salamanca, en la que consta que desde el día de San Lucas de 1691 preparaban un curso de decretales, AUSA, Registro de pruebas testificales, libro, 672 , ff. $147 \mathrm{r}-147 \mathrm{v}$.

41. Martín Gaite, Carmen, Macanaz, otro paciente (...). Op. cit., pp. 143-146 y 215-219.

42. Castro, Concepción de. A la sombra (...). Op. cit., pp. cit., pp. 251-252.

43. Vivanco sería recolocado de su cargo en la secretaría de Justicia de la desaparecida Cámara de Castilla (que desempeñaba desde 1705), al ser nombrado en la Nueva Planta titular de la secretaría de la Sala de Gobierno del consejo, Escudero López, José Antonio. Los secretarios de Estado $y$ del Despacho, 1474-1724 (vol. III). Madrid: Instituto de Estudios Administrativos, 1979, p. 742. $814, \mathrm{~s} / \mathrm{f}$.

44. Será designado Secretario de la Sala de Justicia del consejo, AGS, Gracia y Justicia, legajo

45. Nombrado secretario de la Sala de Provincias; su hijo, Fernando Francisco de Quincoces será informado favorablemente por Macanaz para la provisión de la plaza de juez mayor de Vizacaya a comienzos de septiembre de 1714, AGS, Gracia y Justicia, legajo 133, s/f.

46. Titular de la secretaría de la Sala Criminal, será otro ejemplo de recolocación procedente de la Cámara de Castilla, donde ocupaba -desde septiembre de 1706- la secretaría de Estado, GuERRERO Elecalde, Rafael. Las élites vascas (...). Op. cit., p. 118. 
AUGE, CAÍDA Y CONTINUIDAD DE UNA ÉLITE DE GOBIERNO. NOMBRAMIENTOS DE NUEVA PLANTA...

Anexa al consejo de Castilla, la Sala de Alcaldes de Casa y Corte también recibirá una nueva organización en noviembre de 1713; se nombrarán tres presidentes, Juan de Riomol y Quiroga, Francisco de Henao $^{47}$ y Ambrosio Bernal, quienes presidirán por este orden las tres salas en las que se organizaba el organismo ${ }^{48}$. Un número igual de Alcaldes y Tenientes de Alcalde (dieciocho cada uno), un fiscal, Lorenzo González Faustino ${ }^{49}$, dos abogados reales, Juan Fernández de Salinas Berrocal ${ }^{50}$ y Diego de Alcañiz y Rojas, formaban junto a los cuatro secretarios en jefe, Pascual Félix de la Sala, Juan Baustista de Orrentía, Francisco Graciano y Juan Amador de Azcuitía, el cuerpo principal de la renovada Sala de Alcaldes de Casa y Corte C. $^{51}$

El consejo de Indias, por su parte, contará también con una triple presidencia que recaerá inicialmente en el Conde de Frigiliana, Alonso Pérez de Araciel $^{52}$ y Gonzalo Machado. Los veinte consejeros que figuran en la Nueva Planta se diferenciarán entre togados y de capa y espada (diez cada uno); un fiscal, Martín de Miraval ${ }^{53}$, dos abogados generales (cercanos a Macanaz), Pedro Gómez de la Cava ${ }^{54}$ y Baltasar de Acevedo $^{55}$, junto a los tres secretarios, Francisco de Castejón ${ }^{56}$, Bernardo Tinajero ${ }^{57}$ y

47. Su hermano, Bartolomé Henao Larreategui, será propuesto por Macanaz para una plaza de fiscal en la Audiencia de Pamplona. Posteriormente, volverá a ser propuesto para la fiscalía de la Chancillería de Valladolid, AGS, Gracia y Justicia, legajo 133, s/f.

48. Junto a una cuarta sala plenaria formada por la reunión de los tres presidentes, los dieciocho alcaldes y el secretario Pascual Félix de la Sala, AGS, Gracia y Justicia, legajo 814, s/f.

49. También favorecido por Macanaz, había sido propuesto para una plaza de abogado general en el consejo de Indias, AGS, Gracia y Justicia, legajo 133, s/f.

50. Propuesto por Macanaz para una plaza de abogado general en Hacienda, se referirá a él como «el maior letrado que en toda la sala ai», AGS, Gracia y Justicia, legajo 133, s/f.

51. BNE, Ms. 11. 263, f. 2v.

52. Consejero de Indias desde 1702, será miembro de una saga familiar de origen riojano bien conectada con la administración; varios de sus hermanos ostentarán cargos antes, durante y después de la Nueva Planta, como García (presidente cuarto del consejo de Castilla) o Vicente (presidente segundo del consejo de Órdenes reformado): Dedieu, Jean-Pierre. La muerte del (...). Op. cit., pp. 509-510.

53. Hermano del consejero de Castilla Luis F. Miraval y Spínola, Martín, colegial en el salmantino Colegio mayor de Cuenca, había coincidido con Macanaz en la Universidad de Salamanca (AUSA, Matrículas, Libro 399, f. 9r). Durante su empleo como fiscal del consejo de Indias, formará junto a Macanaz la propuesta de reforma del tribunal de la Inquisición: GARCíA-HeviA, José María. Macanazy su (...). Art. cit., pp. 218-327.

54. Primer abogado general en Indias, Macanaz se referirá a él como el «maior letrado que se conoce», AGS, Gracia y Justicia, legajo 133, s/f.

55. Segundo abogado general del consejo, será llamado en abril de 1714 al de Castilla para cubrir la plaza de abogado general vacante tras la promoción de Ulloa, vid. Coronas González, Santos Manuel. Ilustración y derecho (...). Op. cit., p. 48.

56. Nombrado primer secretario en jefe del consejo de Indias, Castejón había participado en la puesta en marcha de la administración filipina, donde había ocupado cargos en los consejos de Hacienda e Italia antes de su ascenso a la secretaría en el de Indias en 1713. Vid. Guerrero ElECALDE, Rafael. Las élites vascas (...). Op. cit., pp. 100-101.

57. Segundo secretario en jefe del consejo, Tinajero - protegido de Orry- será otro ejemplo de recolocación en la Nueva Planta, al haber servido con anterioridad en la secretaría de Nueva España 
Diego de Morales, completaban el personal de un consejo al que se dotaba de tres salas, una Plenaria, otra de Gobierno y una tercera de Justicia ${ }^{58}$.

El consejo de Hacienda destacará por la importante presencia de personal cercano y bien relacionado con las principales autoridades del momento. Al frente, cuatro presidentes y un veedor general. Los cuatro primeros serán el obispo de Gironda ${ }^{59}$, el marqués de Campoflorido ${ }^{60}$, Sebastián García Romero y Manuel Antonio de Acevedo; Orry, veedor general, se garantizaba «tener siempre el primer lugar y la primera plaza en todas las salas de este Tribunal» ${ }^{61}$. El francés asumía así una posición central en el consejo, presidiendo y tomando parte activa en las reuniones de las cinco salas en las que quedaba dividido (consejo Pleno y salas de Gobierno, Justicia, Millón y Criminal) ${ }^{62}$. Dieciocho consejeros togados y dieciocho de capa y espada formaban la plantilla de ministros. Los dos fiscales generales serán Mateo Pérez Galeote y Lorenzo Mediana ${ }^{63}$, mientras que Alfonso Castellanos ${ }^{64}$, Francisco Molano, Francisco Melgar ${ }^{65}$ y Andrés González de Barcia ${ }^{66}$ (todos favorecidos de Macanaz), serán nombrados abogados generales. Cinco secretarios en jefe, Andrés Elcorobarrutia, Francisco Díaz Román, José Apaolaza, Pedro Gómez

del mismo consejo (1710-1711). Tras el decreto de división de las secretarías del Despacho Universal (noviembre de 1714), será designado titular de Marina e Indias. Vid. López-Cordón Cortezo, María Victoria. Instauración dinástica y (...). Art. cit., pp. 106-107.

58. Las competencias del consejo relativas a la gestión de las rentas de las posesiones de Ultramar se verán mediatizadas por la Junta Mixta Indias-Hacienda. Establecida en el mismo decreto, se confiará la presidencia de esta institución al obispo de Gironda, reuniendo a tres consejeros de Hacienda, tres de Indias, dos fiscales (uno de cada consejo) y un secretario. Vid. Francisco Olmos, José María de. Los miembros del Consejo de Hacienda (1722-1838) y Organismos económico-monetarios. Madrid: Castellum, 1997, p. 385.

59. Lorenzo Armengual, obispo de Gironda, compatibilizaba la presidencia de Hacienda con una plaza de consejero en Castilla. Colaborador habitual del grupo hispano-francés liderado por Grimaldo, había sido gobernador de Hacienda en dos ocasiones, primero entre 1705-1709 y después a partir de 1711, vid. CASTRO, Concepción de. A la sombra (...). Op. cit., pp. 125-145.

60. Colaborador del equipo de Grimaldo, Campoflorido poseía una amplia trayectoria en Hacienda, donde había sido Tesorero Mayor de Guerra (1707-1709) y gobernador del consejo hasta 1711. Vid. Dubet, Anne. "Comprender las reformas de Hacienda a principios del siglo XVIII. La buena administración según el marqués de Campoflorido". HMiC: història moderna i contemporània, 2012, 10, pp. 20-52.

61. AGS, Gracia y Justicia, legajo 814, s/f.

62. Ibidem.

63. Miembro del grupo de agentes felipistas que habían colaborado en la puesta en marcha de la nueva Audiencia de Aragón en 1711: Guerrero EleCAlde, Rafael, Las élites vascas (...). Op. cit. p. 435.

64. Colegial mayor del Rey en la Universidad de Alcalá de Henares, Castellanos formará parte del grupo de promocionados por Macanaz durante la Nueva Planta. En 1714 será propuesto por don Melchor para una plaza de consejero en Castilla, AGS, Gracia y Justicia, legajo 133, s/f.

65. El abogado Melgar será propuesto por Macanaz para la plaza de consejero de Castilla vacante tras el cese de Luis del Curiel, AGS. Gracia y Justicia, legajo 133, s/f.

66. Habitual de la tertulia en la residencia del marqués de Villena -patrón de MacanazGonzález de Barcía recibirá también la favorecida atención de don Melchor, quien se referirá a él como "muy seguro y gran letrado", AGS, Gracia y Justicia, legajo 133, s/f. 
Lozano y Simón López de Humera, junto a doce relatores de cuentas, cerraban la nómina del personal de Hacienda ${ }^{67}$.

El último de los consejos reformado en noviembre de 1713 será el de Órdenes, quedando configurado en torno a dos presidencias que recaerán en el marqués de Bedmar ${ }^{68}$ y Vicente Pérez Araciel. Doce consejeros togados, un fiscal, Diego Santos de San Pedro ${ }^{69}$, un abogado general, Juan Rosillo de Lara ${ }^{70}$ y un secretario en Jefe, Miguel Fernández Durán ${ }^{71}$, completaban el resto de empleos. La organización del consejo seguía una estructura tripartita correspondiente a un consejo Pleno y otras dos salas de Justicia y Gobierno ${ }^{72}$.

El resultado de las medidas anteriores venía a reforzar el papel del consejo de Castilla como órgano director de la vida política de la monarquía, constituyéndose tras los decretos de 1713 -como recuerda Domínguez Ortiz-, en la sede donde tendrá lugar la lucha entre partidarios y detractores de las reformas ${ }^{73}$. Reducidas competencias y soberanía en el resto de consejos, lo que interesará a partir de entonces será asegurar el control del órgano que marcará las directrices de la política de Felipe V. Así se pondrá de manifiesto en la reforma del consejo de Guerra, momento que será aprovechado para llevar a cabo una primera depuración de consejeros, reemplazados a su vez por otros tantos cercanos al fiscal Macanaz.

El desarrollo del conflicto sucesorio y la especial configuración del consejo de Guerra -vinculado institucionalmente con el de Estado- retrasarán su reforma hasta el 23 de abril de $1714^{74}$. Su nueva organización seguía reservando la presidencia al monarca; un cuerpo de doce consejeros (divididos entre seis militares ${ }^{75}$

67. BNE, Ms. 11. 263, ff. 1v-2r.

68. Juan José Domingo de la Cueva y Enríquez, marqués de Bedmar, será confirmado como primer presidente del consejo de Órdenes, cargo que ya ostentaba con anterioridad a la reforma de noviembre de 1713. Vid. Troyano Chicharro, José Manuel. "La casa de la Cueva en el Bedmar del S. XVIII». Sumuntán, 2001, 14, pp. 63-74.

69. Tarilonte Díez, José Antonio. "Señorío de Baños». Publicaciones de la Institución Tello Téllez de Meneses, 1996, 67, pp. 169-180

70. El abogado Juan Rosillo de Lara iniciará su carrera en la administración en el consejo de Órdenes, del que había sido agente y fiscal interino durante el reinado de Carlos II, FAYARD, Janine. "Los ministros del consejo real de Castilla». Hidalguía, 1981, 165, p. 192.

71. Estrecho colaborador de José Grimaldo, en 1706 entrará a formar parte de la oficialidad de la secretaria del Despacho de Guerra y Hacienda, desde donde iniciará una notable trayectoria que lo llevará en 1714 a convertirse en titular de la misma. Antes de vincularse a la secretaría de Grimaldo, había desempeñado ya el cargo de secretario del consejo de Órdenes, LóPEz-Cordón Cortezo, María Victoria. Instauración dinástica y (...). Art. cit., p. 106.

72. Álvarez-Coca González, María Jesús. "El Consejo de órdenes Militares». Cuadernos de Historia Moderna, 1994, 15, pp. 297-323, espec. 311-312.

73. Domínguez Ortiz, Antonio. Sociedad y Estado en el siglo XVIII español. Barcelona: Ariel, 1976, p. 92.

74. Andújar Castillo, Francisco. Consejo y consejeros (...). Op. cit., pp. 35-36.

75. Se nombra cabo y decano de los seis consejeros militares al marqués de Bedmar (presidente del consejo de Órdenes y consejero de Estado). Ibídem., p. 40. 
y seis togados), un secretario en jefe, Martín de Sierralta ${ }^{76}$, un fiscal general, Sebastián de Montufar ${ }^{77}$ y dos abogados generales, Tomás de Sala y Agustín de Montiano, ocupaban las plazas del consejo $^{78}$.

Los ministros togados de Guerra serán nombrados -según el decreto- entre los presidentes y consejeros del resto de consejos, procediendo en esta ocasión todos del de Castilla, desde el decano, Juan Antonio Torres Castejón -segundo presidente en aquel- hasta los cinco restantes, entre los que se hallaban el conde de Gondomar, Pedro Colón de Larreategui, el conde de Gerena, Antonio Jurado y Luis Ramírez (salvo Jurado, el resto colegiales mayores). El traspaso de estos a Guerra se justificará en la avanzada edad y los numerosos achaques de salud que les impedían asistir regularmente a las reuniones del consejo de Castilla. Siendo cierto en la mayoría el argumento de la edad (Gondomar -ochenta y tres años-, Torres Castejón -ochenta y dos-, Colón de Larreategui y Gerena -sesenta y tres-) ${ }^{79}$, parece que pesaron más otras razones de orden político, como puede inferirse en el caso del conde de Gerena, a quien el propio Macanaz había propuesto jubilar "pues el lo pidió a S. M. quando la nueva planta, no asiste, es muy viejo y de poca salud y todo es oponerse a cuanto se hace ${ }^{80}$.

La jugada se completará con el nombramiento de nuevos consejeros que vinieran a cubrir las plazas vacantes dejadas por los que pasaban a Guerra; es entonces cuando se manifiesta más claramente el verdadero interés por el control del consejo de Castilla ${ }^{81}$, al ser designados para este, personas de acreditada cercanía y reconocimiento del propio Macanaz. Tales serán los casos ya citados de los abogados generales del consejo, Villalpando y Ulloa, así como los alcaldes de Casa y Corte, Apóstol Andrés de Cañas ${ }^{82}$ y Álvaro de Castilla ${ }^{83}$ o el catalán Francisco Ametller $^{84}$. Una plaza quedaba sin ser provista.

76. Datos sobre la trayectoria de Martín Sierralta, GuERrero EleCALDE, Rafael, Las élites vascas (...). Op. cit., p. 520 .

77. AGS, Gracia y Justicia, legajo 814 , s/f.

78. Los abogados generales serán nombrados tras la entrada en vigor de la reforma, Gaceta de Madrid, 18 de diciembre de 1714, f. 203.

79. FAYARD, Janine. Los ministros del (...). Op. cit., 167-192.

80. AGS, Gracia y Justicia, legajo 133 , s/f.

81. Castellano Castellano, Juan Luis, Gobierno y poder (...). Op. cit., pp. 60-62.

82. Colegial mayor en el de Cuenca, Macanaz había propuesto con anterioridad a Apóstol de Cañas para la plaza de fiscal en el consejo de Hacienda, AGS, Gracia y Justicia, legajo 133, s/f. A finales de 1714 intentará en vano su nombramiento como consejero de la Inquisición. Vid. García-Hevia, José María. Macanaz y su (...). Art. cit. pp. 265-266.

83. Colegial Mayor de Cuenca en Salamanca, en el momento de su nombramiento era presidente electo de la Audiencia y Chancillería de Valencia, AHN, Consejos, libro, 734, f. 94 v.

84. Declarado pro-borbónico, había colaborado en la puesta en marcha del gobierno y justicia de la Cataluña borbónica. Hombre fuerte de Macanaz en Cataluña, vid. García Fuertes, Gemma. "Francesc Ametller i Perer (1657/8-1726). Un jurista català al servei de Felip V". Pedralbes: revista d’història moderna, 2008, 28/1, pp. 165-202. Notas sobre la trayectoria de Ametller. Vid. MoLAS Ribalta, Pere. "Aragón en el Consejo de Castilla». Cuadernos Dieciochosistas, 2010, 2, pp. 13-35. 
AUGE, CAÍDA Y CONTINUIDAD DE UNA ÉLITE DE GOBIERNO. NOMBRAMIENTOS DE NUEVA PLANTA...

Estos cambios implicarán a su vez los primeros trasvases de personal entre consejos. Para las plazas de abogado general de Castilla se preferirá un perfil técnico además de cierta cercanía al fiscal general, razón por la que se buscará a dos abogados generales en ejercicio, Alfonso Castellanos -primero en Hacienda- y Baltasar de Acevedo -segundo en Indias-. Las plazas dejadas por éstos serán cubiertas más adelante por personal secundario de la administración cercano también a Macanaz, como su primer sustituto fiscal, Manuel de Toledo ${ }^{85}$ y Juan Manuel de la $\mathrm{Chica}^{86}$.

\section{LA REFORMA EN LA ENCRUCIJADA: LOS ÚlTIMOS PROMOCIONADOS DE LA NUEVA PLANTA}

Los cambios operados en el seno del gobierno por consejos crearán pronto una larga lista de damnificados y descontentos. Tema recurrente en la sátira política del momento -como demostró Egido López- la crítica a la reforma, a sus ejecutores y protagonistas, llevará a muchos a tomar la pluma para manifestar las desagradables consecuencias de la novedad y el lamentable estado de lo político que seguirá en los meses siguientes ${ }^{87}$.

La oposición a la Nueva Planta se dejará notar también en el terreno de la práctica política. Muchos consejeros contrarios a la nueva organización comenzarán a entorpecer su desarrollo, dilatando la toma de decisión y obstaculizando la tramitación de los negocios ${ }^{88}$. La oposición se tornará en abierta cuando el consejero de Castilla, Luis del Curiel, llegue a enfrentarse nada menos que al poderoso fiscal general de la institución. La ocasión se presentará con motivo de la discusión en el consejo del Pedimento fiscal de los cincuenta y cinco párrafos elaborado por Macanaz. El texto presentado al consejo a finales de diciembre de 1713, debía servir de base al representante español que negociaba en la corte de Luis XIV un nuevo acuerdo con la Santa Sede ${ }^{89}$. Filtrado por Curiel al inquisidor general Del Giudice, este iniciará los trámites que culminarán con la censura y condena del Pedimento en agosto de $1714^{90}$.

La distancia entre Curiel y Macanaz era más que evidente, de hecho, quedaba de manifiesto en el voto particular que a modo de réplica había elevado el propio

85. Macanaz se referirá a él en términos de "tan gran letrado como toda la corte conoce, y muy del rey, y en las materias de Hacienda muy diestro", AGS, Gracia y Justicia, legajo 133, s/f.

86. AHN, Consejos, libro 734, ff. 140r-143r.

87. EGIDO López, Teófanes. Opinión pública y oposición al poder en la España del siglo XVIII (1713-1759). Segunda edición. Valladolid: Fundación española de Historia Moderna, 2002, pp. 101110 .

88. Dedieu, Jean-Pierre. "La Nueva Planta (...)». Art. cit., pp. 120-121.

89. Sobre la negociación: MARTín MARCos, David. El papado y la Guerra de Sucesión española. Madrid: Marcial Pons, 2011, pp. 214-215 y 212-222.

90. MarTín GaITE, Carmen. Macanaz, otro paciente (...). Op. cit. pp. 266-280. 
Curiel contra el texto anterior de don Melchor ${ }^{91}$. Crítico con el sentido regalista de las medidas propuestas en el Pedimento, Curiel hará gala de un reformismo moderado cuya fuente de reforma no excluiría al Papa, al contrario, el remedio contra los excesos cometidos por Roma debía pasar por el acuerdo entre ambas autoridades, la real y la pontificia ${ }^{92}$.

A la diferencia ideológica se unía además la política. Parece que desde el comienzo de la Nueva Planta, Curiel se había convertido en la cabeza visible de la oposición al fiscal general dentro del propio consejo. Sánchez Ulloa, fiel colaborador del fiscal, alertaba de las precauciones a seguir con Curiel, a quien acusaba de liderar una liga de consejeros "contrarios a las regalías», es decir, al propio Macanaz. El celo de este grupo contra el fiscal había aumentado tras la condena del Pedimento por Del Giudice, dando lugar a una serie de reuniones y tertulias privadas de las que daba cuenta Ulloa, informando de la presencia en ellas -además de Curiel- de los consejeros Arana, Araciel, Andía, Lagrava y Morales ${ }^{93}$. La tensión provocada por la actuación del inquisidor general, haría descartar cualquier medida de contención que no pasara ya por asegurar totalmente el control de la institución. De ahí la nueva oleada de ceses y nombramientos que se sucederán a lo largo de la segunda mitad de 1714 en el consejo de Castilla y en el resto de órganos de la polisinodia.

Los cambios implicarán en primer lugar a la presidencia múltiple del consejo; el marqués de Andía y García Pérez Araciel, presidentes tercero y cuarto, perderán su empleo, aquel "por inútil», mientras que Pérez Araciel "por haber concurrido en lo executado por el consejo de la Inquisición contra la regalía y autoridad del Rey y mostrarse en todas ocasiones opuesto a la defensa de los intereses de S. M.» ${ }^{94}$. Ambos, no obstante, serán designados asesores en el consejo de Estado ${ }^{95}$. Por motivos de salud serán relegados de sus cargos los presidentes primero y segundo, Francisco Rodríguez Medarozqueta (a quien se ordenaba pasar a su obispado de Sigüenza) y Torres Castejón, que había recalado ya en el de Guerra como decano de los ministros togados. Para cubrir sus plazas se recurre a personal de Nueva Planta, es decir, administradores que desde noviembre de 1713 desempeñan sus funciones en alguno de los consejos reformados, con preferencia los de Castilla y Hacienda. Miguel de Guerra, hasta ese momento presidente quinto de Castilla, pasará a ocupar la primera presidencia; le siguen los consejeros, marqués de Aranda y Francisco Portell, como presidentes segundo y tercero. Las presidencias cuarta

91. RAH, Mss. 9/1510, ff. 61r-129v.

92. La posición de Curiel y la reacción al texto del Pedimento Fiscal de Macanaz, vid. HernáNDEZ Franco, Juan y PRECIOSO IZQuiERdo, Francisco. "Discursos enfrentados en los albores de la Monarquía borbónica. Reacciones al Pedimento Fiscal de Macanaz". Mediterranea-ricerche storiche, 2014, 30, pp. 77-82.

93. Martín Gaite, Carmen. Macanaz, otro paciente (...). Op. cit., pp. 279-280.

94. AGS, Gracia y Justicia, legajo 814, s/f.

95. Gaceta de Madrid, 18 de diciembre de 1714, f. 203. 
y quinta se reservarán a sendos presidentes del consejo de Hacienda, Sebastián García Romero y Manuel Antonio de Acevedo ${ }^{96}$.

El cuerpo de consejeros de Castilla también sufrirá notorios cambios, comenzando por la liga de críticos con el fiscal formada por Curiel, Francisco de Arana y Pedro José Lagrava. Los tres perderán su empleo, siendo relevados por otros tantos favorecidos de Macanaz, como el consejero togado de Hacienda, Jerónimo Pardo $^{97}$, el abogado general cuarto del mismo consejo, Andrés González de Barcia y el fiscal de la Sala de Alcaldes de Casa y Corte, Lorenzo González Faustino. Las plazas de los consejeros de Castilla promovidos a presidentes (Aranda y Portell) serán cubiertas por otros dos favorecidos del fiscal, caso del primer abogado general de la institución, Alfonso Castellanos y el abogado general en Órdenes, Juan Rosillo de Lara. Pedro Gómez de la Cava, primer abogado general en Indias y Francisco Molano (misma función en Hacienda), completaban la serie de nuevos consejeros de Castilla ${ }^{98}$ en sustitución del conde de Valdelaguila ${ }^{99}$ y Luis de Miraval $^{100}$.

Los cargos auxiliares del consejo serán igualmente renovados por personas cercanas a Macanaz. Juan Fernando Salinas, abogado general en la Sala de alcaldes de Casa y Corte, sustituirá a Alfonso Castellanos como primero en Castilla, mientras que la plaza dejada por la promoción de Baltasar de Acevedo a una de las presidencias de Hacienda, se confiará a Francisco Riaza, sustituto fiscal segundo de Macanaz ${ }^{101}$. A primeros de enero de 1715 se nombrarán dos nuevos sustitutos fiscales, José Moscoso y Bernardo Muñoz ${ }^{102}$.

Las plazas del resto de consejos alteradas por los cambios en Castilla serán provistas también a finales de 1714. En Hacienda, las presidencias de García Romero y Manuel Antonio Acevedo recaerán en Juan de Riomol (primer presidente de la Sala de Alcaldes de Casa y Corte) y Baltasar de Acevedo (abogado general en Castilla) ${ }^{103}$. Entre los consejeros se producirán tres nuevos nombramientos correspondientes a las plazas dejadas por la promoción del murciano Juan Valcárcel

96. Ibídem, f. 203.

97. La trayectoria de Pardo estará ligada al entorno del VIII marqués de Villena, con quien había coincidido en Nápoles durante la Guerra de Sucesión; tras la liberación de Gaeta en 1712, formará parte del grupo de primeros académicos de la Real Academia Española, FAYARD, Janine, Los ministros del (...). Art. cit., p. 192.

98. Gaceta de Madrid, 18 de diciembre de 1714, ff. 203-204.

99. Pasará al consejo de Guerra a ocupar la plaza vacante dejada por el fallecimiento de Luís Ramírez de Arrellano en julio de 1714, AGS, Gracia y Justicia, legajo 814, s/f.

100. En diciembre de 1714 será nombrado embajador extraordinario en los Estados Generales de Holanda, FayArD, Janine, La tentative de (...). Art. cit., p. 282.

101. AGS, Gracia y Justicia, legajo 814, s/f.

102. Gaceta de Madrid, 1 de enero de 1715, f. 8.

103. AGS, Gracia y Justicia, legajo 814 , s/f. 
Dato a la presidencia de la Chancilleria de Valencia ${ }^{104}$, Manuel de Fuentes a la presidencia primera de la Sala de alcaldes de Casa y Corte y la ya citada de Jerónimo Pardo. Los dos primeros serán sustituidos por los alcaldes de Casa y Corte, Diego de Guevara y Baltasar Álvarez de Medrano, mientras que Raimundo de Villacís, alcalde de Hijosdalgo de Valladolid, hará lo propio con la plaza de Pardo ${ }^{105}$. Las tres abogacías generales vacantes en Hacienda serán cubiertas por Manuel de Toledo, sustituto del fiscal Macanaz, Francisco de Mera, sustituto en Hacienda y Antonio Cala de Bargas, oidor en la Audiencia de Valencia ${ }^{106}$.

En el consejo de Indias, por su parte, se designan dos nuevos abogados generales que vendrán a ocupar las plazas de Gómez de la Cava y la vacante dejada meses atrás por Baltasar de Acevedo, decantándose por sendos abogados conocedores de la dinámica del consejo y los negocios indianos. Así, se elige para la primera a Diego Valdés Girón, oidor de la Audiencia de Zaragoza y también de la Casa de Contratación, mientras que para la segunda -como adelantamos- se hará lo propio con otro favorecido de Macanaz, el abogado Juan Manuel de la Chica, oidor de la Casa de Contratación y "ha dieciséis años que sirve en el Consejo de Indias ${ }^{107}$.

La promoción de Juan Rosillo de Lara al consejo de Castilla, hará necesario el nombramiento de un nuevo abogado general en el consejo de Órdenes, cargo que recaerá en Tomás de Molinillo, alcalde de Casa y Corte. Finalmente, los nombramientos publicados el 18 de diciembre de 1714 se completarán con una lista de ocho nuevos alcaldes de Casa y Corte así como la provisión de numerosos empleos en la administración territorial ${ }^{108}$.

¿INTEGRACIÓN O EXCLUSIÓN? LOS FAVORECIDOS EN LA CONTRARREFORMA DE 1715

La llegada al poder del nuevo equipo patrocinado por la segunda esposa de Felipe V, la parmesana Isabel de Farnesio, hará quebrar la hegemonía de los reformistas en el gobierno. El cese de Macanaz y Orry a comienzos de febrero de $1715^{109}$, pondrá en cuarentena la Nueva Planta de los consejos. Un primer decreto, fechado el 28 de marzo, anunciaba ya la restitución a sus plazas de consejeros de Castilla a los cesados tras los sucesos que terminaron con la condena del

104. Molas Ribalta, Pere. La Audiencia borbónica del reino de Valencia (1707-1834). Alicante: Universidad de Alicante, 1999, p. 47

105. AGS, Gracia y Justicia, legajo 814, s/f.

106. Macanaz había elogiado ya su experiencia de "más de veinte años de abogado en Madrid", AGS, Gracia y Justicia, legajo 133, s/f.

107. AGS, Gracia y Justicia, legajo 814 , s/f.

108. Gaceta de Madrid, 18 de diciembre de 1714, f. 204.

109. Gaceta de Madrid, 12 de febrero de 1715, f. 28. 
AUGE, CAÍDA Y CONTINUIDAD DE UNA ÉLITE DE GOBIERNO. NOMBRAMIENTOS DE NUEVA PLANTA...

Pedimento ${ }^{110}$, es decir, Torres Castejón, Pérez Araciel, el marqués de Andía, Curiel, Arana y Lagrava.

La vigencia de la Nueva Planta se mantendrá hasta el 9 de junio, día en el que se publicará otro decreto por el que se restablecerá la organización de todos los consejos al pie anterior a la reforma de 1713, incluyendo la restitución de la Cámara de Castilla. La contrarreforma -en expresión de Escudero López ${ }^{111}$ - se completaría con la serie de decretos que se encargarán caso por caso de la composición y estructura de cada consejo. Todo ello supondrá la desaparición de las novedades institucionales introducidas en noviembre de 1713, lo que significaba una drástica reducción del personal promocionado hasta entonces. La medida confirmará la pérdida de los empleos de la mayoría de favorecidos meses atrás por Macanaz. No obstante, se contarán algunas excepciones como la del consejero Álvaro de Castilla, el propio José Rodrigo Villalpando -que permanecerá en el consejo aunque degradado a fiscal criminal-, o los casos de Manuel Antonio de Acevedo y Sebastián García Romero, quienes serán rebajados de presidentes a consejeros ${ }^{112}$. Otros, como Martín de Miraval, será encargado con un de las dos fiscalías que se creaban en el de Indias ${ }^{113}$. Mayor continuidad se observa en el consejo de Hacienda con casos como los de Baltasar de Acevedo, que caerá de la presidencia quinta a la fiscalía de Millones, el de José de Aperregui, que dejará su plaza de consejero por la fiscalía de Justicia, o la temprana vuelta de Francisco Melgar como fiscal a finales de $1716^{114}$.

El resto sufrirá un alejamiento -si bien temporal en la mayoría- de los empleos a los que habían sido promocionados durante la Nueva Planta. Esta situación llevará a muchos, antes incluso de conocer su posible continuidad, a remitir sentidos memoriales con los que tratar de quedar a salvo de la contrarreforma. El caso de Tomás Fernández Molinillo, abogado general en Órdenes, puede ser indicativo de la sensación de desconcierto y confusión experimentada por gran parte de los favorecidos durante los meses siguientes a la derogación. A finales de julio de 1715, Fernández Molinillo se había apresurado a presentar ya su memorial, el cual no se llegará a remitir a la Cámara de Castilla "por no estar reformado este ministro y no haber bajado la planta del consejo de Órdenes» ${ }^{115}$.

La mayoría de los memoriales seguirá una estructura similar, siendo en general una literatura bastante autocomplaciente, exculpatoria e interesada en un objetivo común. Todos manifestarán cierta extrañeza al quedar privados de sus plazas. Quienes pueden, comenzarán recordando las pérdidas y quebrantos ocasionados

110. AAE, Correspondencia Política (España), Mss. 239, f.213r.

111. Escudero LóPEz, José Antonio. La reconstrucción de (...). Op. cit., pp. 109-111.

112. FAYARD, Janine. La tentative de (...). Art. cit., p. 282.

113. AGS, Gracia y Justicia, legajo 814, s/f.

114. Francisco Olmos, José María de. Los miembros del (...). Op. cit. p. 377

115. El resto de memoriales citados y entrecomillas, hasta nueva nota, AGS, Gracia y Justicia, legajo $814, \mathrm{~s} / \mathrm{f}$ 
durante la guerra al tomar partido por la causa de Felipe V, como Francisco Ametller, quien traerá a la memoria haber «abandonado mi Patria y hacienda, confiscada nueve años por los enemigos y rebeldes (...) rodado el mundo otros tantos años por la justa causa del Rey, con mujer, hijos y toda la familia a cuestas». Los estudios, oposiciones a cátedras y demás méritos académicos serán igualmente puestos de relieve. Otro tanto ocurrirá con la enumeración de los cargos y años de experiencia y servicio en la administración. Adornados con toda clase de recomendaciones, ocuparán la parte central de las reivindicaciones. Manuel Fuentes, por ejemplo, dedicará tres cuartas partes de su memorial a repasar uno por uno sus múltiples empleos, desde la fiscalía de la Audiencia de Sevilla y la Chancillería de Granada, su nombramiento en la nueva Audiencia creada en Zaragoza, la fiscalía del consejo de Hacienda, la plaza de consejero en la Nueva Planta del mismo consejo, hasta "que mereció ser promovido a la primera presidencia de la Sala de Alcaldes", en total, "casi treinta años en estos servicios tan dichosos por haber sido en el de VM».

Escasas serán las alusiones a Melchor Macanaz. La mayoría presentará su paso por la Nueva Planta sin mayor diferencia respecto al ejercicio de cargos anteriores, prevaleciendo el nombramiento recibido por parte del rey a cualquier otra consideración sobre mentores o patrocinadores. Solo en Luis Sánchez Ulloa encontramos una velada referencia a don Melchor. Tras lamentar su injusto padecer por la pérdida de la plaza de consejero de Castilla, descargará cualquier responsabilidad personal, argumentando no haber «seguido mas parcialidad que la de la razón y justicia y aquello que mi corto talento me ha dictado por mejor (...), tratándome tan mal como a el ausente con quien pueden tener el pleito pero no conmigo».

Referido el lastimoso estado y la ruina derivada de la pérdida de sus empleos o un destino de inferior calidad y renta, dirigirán al rey una súplica final en la que reducirán lo principal de sus peticiones. Tal será el caso de Clemente Ussel y Guimbarda, quien después de recordar la "falta de medios que padece para poder mantenerse en esta corte, habiendo vendido todo lo que tenía", solicitará al monarca le despache orden "para que pueda retirarse al rincón de su Casa, a Granada, a asistir a su mujer»; otros, como Ametller, solicitará al rey el "consuelo y alivio que necesito (...) será restituyéndome en mi plaza de Castilla (...) o con aumento de sueldo en la de consejero de Guerra».

Sin embargo, más allá de los memoriales, parece que la voluntad será la de integrar en el nuevo escenario político inaugurado en junio de 1715 al colectivo de favorecidos por el ex fiscal, de forma que la mayoría lograrán ser acomodados conforme vacara una plaza o surgiera una nueva institución. En una relación manuscrita elaborada tras la derogación de la Nueva Planta de los consejos, se cifrará en cuarenta y seis el número de consejeros, abogados generales, fiscales, sustitutos y alcaldes de casa y corte, el total de desplazados como consecuencia de los decretos restauradores de 1715 . El documento se encargará también de señalar el destino posterior de alguno de ellos (APÉNDICE I). 
AUGE, CAÍDA Y CONTINUIDAD DE UNA ÉLITE DE GOBIERNO. NOMBRAMIENTOS DE NUEVA PLANTA...

Entre los reformados destacará el caso de los consejeros de Castilla. Tras el regreso al consejo de los designados en abril de 1714 para el de Guerra, una nueva terna se nombrará ahora para las plazas togadas en aquel, compuesta en esta ocasión por siete favorecidos de Macanaz, como serán Ametller, Apóstol de Cañas, Gómez de la Cava, Castellanos, Molano, Rosillo de Lara y Pardo. La reducción hasta cuatro de las plazas togadas en Guerra hará que tres de ellos fueran nombrados como ministros supernumerarios ${ }^{116}$. Además de los cargos de fiscal general, abogados generales y sustitutos de fiscal, la "contrarreforma» en Castilla supondrá la desaparición de tres plazas de consejero, las ocupadas por González de Barcia, González Faustino y Sánchez Ulloa, tres de los hombres más significados por su cercanía a Macanaz. El primero recuperará su empleo (previo paso por el consejo de Guerra) a finales de la década de 1720, mientras que el segundo regresaría en 1716 a su cátedra de Prima de leyes en la Universidad de Salamanca ${ }^{117}$. Sánchez Ulloa, por el contrario, será el único de los favorecidos en Castilla cuya suerte parece seguir a la malograda de su amigo y patrón Macanaz, pues no volverá a ocupar cargo alguno en la administración posterior. En otros casos, como el de los alcaldes de Casa y Corte, Juan del Castillo y José Cenzano, serán nombrados tenientes de corregidor en la villa de Madrid, conservando los honores de su antiguo empleo "con obediencia a las primeras plazas que vacaren»" ${ }^{118}$.

Uno de los destinos más socorridos para los reformados de Nueva Planta serán las instituciones territoriales creadas tras la conquista de Cataluña y Mallorca. Destaca el caso de la Audiencia de Cataluña, donde nada menos que siete de los dieciocho ministros que conformarán inicialmente el tribunal serán nombrados entre personal (no catalán) cesado de los consejos de Hacienda, Indias y la Sala de Alcaldes de Casa y Corte ${ }^{119}$. Agustín Montiano, por su parte, será nombrado regente de la Audiencia de Mallorca ${ }^{120}$. La carrera judicial en el resto de Audiencias y Chancillerías también será aprovechada para recolocar a otros tantos reformados; Manuel Fuentes presidirá desde agosto de 1715 la Chancillería de Granada, institución donde irán a parar en 1719 y 1720 los alcaldes Leonardo Vivanco Angulo y Francisco Hernández Rehíllo ${ }^{121}$. El fiscal de la Sala de Alcaldes, Cosme García Talón, será nombrado en febrero de 1716 fiscal de la Audiencia de Sevilla ${ }^{122}$.

116. Gaceta de Madrid, 18 de junio de 1715, f. 100.

117. FAYARD, Janine, Los ministros del (...). Op. cit., p.191.

118. Gaceta de Madrid, 16 de julio de 1715, f. 116.

119. PÉREZ SAmPER, María de los Ángeles. "La Audiencia de Cataluña en el siglo XVIII". Revista de historia moderna: Anales de la Universidad de Alicante, 1995, 13-14, pp. 51-71.

120. Vidal, José Juan. "El Reino de Mallorca del filipismo al austracismo, 1700-1715». En SERRANO Martín, Eliseo (ed.). Felipe Vy su tiempo (vol. II). Zaragoza: Instituto Fernando el Católico, 2004, pp. 151-210.

121. AHN, Consejos, libro, 734, f. $271 \mathrm{v}$.

122. Arias de SAavedra Alias, Inmaculada. "Los fiscales de la Audiencia de Sevilla en el siglo XVIII: notas para su historia». Cuadernos de Historia Moderna, 2011, 36, pp. 129-150. 
La administración local será otro de los medios empleados para dar salida a personal reformado de Nueva Planta, como los consejeros de Hacienda, José de Araque y Agustín Caniego ${ }^{123}$, corregidores electos de Medina del Campo y Cuenca respectivamente. Así mismo, otros dos ministros reformados serán designados para sendas comisiones especiales, uno en Indias, Juan José de Mutiloa, y otro en Murcia, Clemente Usell y Guimbarda ${ }^{124}$.

\section{A MODO DE CONCLUSIÓN}

La continuidad posterior de la mayor parte de los individuos promocionados durante la Nueva Planta dibuja un escenario menos rupturista en cuanto a la élite política que servirá en los consejos en una y otra etapa. Este hecho permite limitar, en primer lugar, el impacto y la dimensión punitiva de la "contrarreforma" de 1715 , medida que afectará de forma desigual y que no impedirá permanecer en la alta administración -en unos casos- o regresar -en otros- a la mayoría. Una diversidad de situaciones fruto de la desigual relación que les unirá a algunas de las figuras más significativas de la Nueva Planta, como el fiscal Macanaz, promotor de la mayoría de los nombramientos, lo que no equivale por sí mismo a una automática identificación con él. A muchos los conocerá simplemente por sus obras literarias, méritos académicos o profesionales, otros, en cambio, sí parecen haber compartido con don Melchor mayor cercanía y complicidad política (Sánchez Ulloa, González de Barcia, Pardo, Villalpando...). Los hombres de Macanaz terminarán siendo, en general, simples favorecidos, personas informadas positivamente por el fiscal, propuestos para tal o cual cargo según su criterio, sin que en puridad merezcan si quiera la consideración de hechuras o criaturas, salvo casos de excepción como Sánchez Ulloa.

Técnicos, muchos de ellos especialistas en el manejo de los papeles en materia de Hacienda o Indias, con años de experiencia acreditada en el mundo de la abogacía o la propia administración, sin razones de peso que justifiquen realmente su alejamiento definitivo del espacio político-administrativo tras la crisis de 1715.

Esta diferencia de relación será determinante, a nuestro juicio, a la hora de evaluar su trayectoria posterior. La mayor parte apenas será vinculada con el ex fiscal, lo que les permitirá una continuidad menos problemática en la administración post-Macanaz. A los más identificados, en cambio, la pérdida inmediata de su empleo podrá verse acompañada de un nuevo destino de inferior categoría, circunstancia que en algunos casos llega a alargarse en el tiempo e incluso -como

123. Moya PINEDO, Jesús. Corregidores y regidores de Cuenca, siglos XV al XIX. Cuenca, 1977, p. 396.

124. GÓMEZ GONZÁLEZ, Inés. «Más allá de la colegialidad: una aproximación al juez de comisión en la España del Antiguo Régimen”. Chronica Nova. Revista de Historia Moderna de la Universidad de Granada, 2011, 37, pp. 21-40. 
Sánchez Ulloa- ver truncada su carrera en la administración. Pero aún entre estos últimos, la mayoría volverá a recuperar sus cargos durante el breve lapso de tiempo que media entre 1715 y 1720, regresando finalmente a las instituciones a las que fueron promovidos durante la Nueva Planta.

Una élite política, en definitiva, que logrará sobrevivir a la desaparición del elemento común a todos ellos, su mentor, protector o simple informador Melchor Macanaz, cuya defenestración apenas se hará extender al personal por él reclutado y promocionado, muchos de los cuales seguirán sirviendo en la administración y gobierno de Felipe $\mathrm{V}$ a lo largo de su reinado.

\section{APÉNDICE DOCUMENTAL (I)}

RELACIÓN DE LOS MINISTROS QUE QUEDARON REFORMADOS POR LOS DECRETOS DE DEROGACIÓN dE LA Planta DEL año 1713. A. G. S. Gracia y Justicia, Leg. 133, S/F.

\begin{tabular}{|c|c|c|}
\hline & $\begin{array}{l}\text { Cargo Nueva Planta } \\
\qquad(1713-1714)\end{array}$ & $\begin{array}{c}\text { Situación posterior } \\
\text { derogación Nueva Planta } \\
(1715)\end{array}$ \\
\hline Señor Dn Francisco Ameller & Del consejo de Castilla & Pasó a Guerra \\
\hline Señor Dn Apóstol de Cañas & Ídem & Idem \\
\hline Señor Dn Alfonso Castellanos & Ídem & Ídem \\
\hline Sr Dn Pedro Gómez de la Cava & Ídem & Ídem \\
\hline Sr Dn Juan Rosillo de Lara & Ídem & Ídem \\
\hline Sr Dn Francisco Molano & Ídem & Ídem \\
\hline Sr Dn Gerónimo Pardo & Ídem & Ídem \\
\hline Sr Dn Luis de Ulloa & Del Consejo de Castilla & \\
\hline Sr Dn Andrés de Barcia & Ídem & \\
\hline Sr Dn Lorenzo Glez. Faustino & Ídem & \\
\hline Dn Juan Fernando de Salinas & $\begin{array}{l}\text { Abogado general } \\
\text { primero del Consejo de } \\
\text { Castilla }\end{array}$ & $\begin{array}{l}\text { Tiene plaza del de } \\
\text { Hacienda para cuando } \\
\text { vuelva de Portugal }\end{array}$ \\
\hline Dn Francisco de Arriaza & $\begin{array}{l}\text { Segundo Abogado } \\
\text { General }\end{array}$ & \\
\hline Dn Manuel de Fuentes & $\begin{array}{l}\text { Presidente primero de la } \\
\text { Sala de Alcaldes }\end{array}$ & $\begin{array}{l}\text { Es Presidente de la } \\
\text { Chancillería de Granada }\end{array}$ \\
\hline Dn Juan Joseph de Mutiloa & Alcalde de Corte & $\begin{array}{l}\text { Pasó a Indias a una } \\
\text { Comisión }\end{array}$ \\
\hline Dn Lorenzo de Cardona & Alcalde de Corte & \\
\hline
\end{tabular}


AUGE, CAÍDA Y CONTINUIDAD DE UNA ÉLITE DE GOBIERNO. NOMBRAMIENTOS DE NUEVA PLANTA..

\begin{tabular}{|c|c|c|}
\hline & $\begin{array}{l}\text { Cargo Nueva Planta } \\
\quad(1713-1714)\end{array}$ & $\begin{array}{c}\text { Situación posterior } \\
\text { derogación Nueva Planta } \\
(1715)\end{array}$ \\
\hline Dn Juan del Castillo & Alcalde de Corte & $\begin{array}{l}\text { Le están concedidos } \\
\text { honores y antigüedad } \\
\text { de esta plaza. Teniente } \\
\text { Corregidor en Madrid }\end{array}$ \\
\hline Dn José Cenzano & Alcalde de Corte & $\begin{array}{l}\text { Le está concedida la } \\
\text { misma merced }\end{array}$ \\
\hline Dn Clemente Usel y Guimbarda & Alcalde de Corte & \\
\hline Dn Leonardo Vivanco Angulo & Ídem & \\
\hline Dn Alonso Uría de Llano & Alcalde de Corte & Es Ministro en Cataluña \\
\hline Dn Francisco Hernández Reíllo & Alcalde de Corte & \\
\hline Dn Cosme Talón & Fiscal de la Sala & $\begin{array}{l}\text { Es Fiscal de la Audiencia } \\
\text { de Sevilla. }\end{array}$ \\
\hline Dn Diego de Barbastro & $\begin{array}{l}\text { Abogado Real primero } \\
\text { de la Sala de Alcaldes }\end{array}$ & $\begin{array}{l}\text { Es Ministro civil en } \\
\text { Cataluña }\end{array}$ \\
\hline Dn Joseph Pasamonte & $\begin{array}{l}\text { Abogado Real segundo } \\
\text { de la Sala de Alcaldes }\end{array}$ & \\
\hline Dn Pedro García de San Román & $\begin{array}{l}\text { Primero sustituto Fiscal } \\
\text { de la Sala de Alcaldes }\end{array}$ & \\
\hline Dn Melchor Fletos & $\begin{array}{l}\text { Segundo sustituto Fiscal } \\
\text { de la Sala de Alcades }\end{array}$ & \\
\hline $\begin{array}{l}\text { Dn Agustín Francisco de } \\
\text { Montiano }\end{array}$ & $\begin{array}{l}\text { Abogado general de } \\
\text { Guerra }\end{array}$ & $\begin{array}{l}\text { Es Regente de la } \\
\text { Audiencia de Mallorca }\end{array}$ \\
\hline Dn Juan Manuel de la Chica & $\begin{array}{l}\text { Abogado general } \\
\text { segundo del Consejo de } \\
\text { Indias }\end{array}$ & $\begin{array}{l}\text { Es Fiscal Criminal de } \\
\text { Cataluña }\end{array}$ \\
\hline Dn Baltasar de Acevedo & & Es Fiscal de Millones \\
\hline $\begin{array}{l}\text { Dn Juan Fco. Santos de San } \\
\text { Pedro }\end{array}$ & & \\
\hline Dn Francisco Apertegui & & Es Fiscal de Justicia \\
\hline Dn Josep de Araque & & $\begin{array}{l}\text { Electo Corregimiento de } \\
\text { Medina del Campo }\end{array}$ \\
\hline Dn Agustín Caniego & & $\begin{array}{l}\text { Electo Corregidor de } \\
\text { Cuenca }\end{array}$ \\
\hline \multicolumn{3}{|l|}{ Dn Jerónimo Sotelo } \\
\hline \multicolumn{3}{|l|}{ Dn Pedro González Torano } \\
\hline Dn Antonio de la Pedrosa & & \\
\hline
\end{tabular}


AUGE, CAÍDA Y CONTINUIDAD DE UNA ÉLITE DE GOBIERNO. NOMBRAMIENTOS DE NUEVA PLANTA...

\begin{tabular}{|l|l|l|}
\hline & \multicolumn{1}{|c|}{$\begin{array}{c}\text { Cargo Nueva Planta } \\
(1713-1714)\end{array}$} & $\begin{array}{c}\text { Situación posterior } \\
\text { derogación Nueva Planta } \\
(1715)\end{array}$ \\
\hline Dn Francisco Ceferino del Villar & & Es Ministro en Cataluña \\
\hline Dn Raymundo de Villacís & & Es Ministro en Cataluña \\
\hline $\begin{array}{l}\text { Dn Baltasar Álvarez de } \\
\text { Medrano }\end{array}$ & & \\
\hline Dn Diego de Guevara & $\begin{array}{l}\text { Primero Abogado } \\
\text { general }\end{array}$ & Es Regente en Cataluña \\
\hline Dn Francisco de Melgar & $\begin{array}{l}\text { Segundo Abogado } \\
\text { general }\end{array}$ & Es Ministro en Cataluña \\
\hline Dn Manuel de Toledo & & \\
\hline Dn Antonio de Cala y Vargas & Primero sustituto Fiscal & \\
\hline Dn Pedro Romo & Segundo sustituto Fiscal & \\
\hline Dn Manuel de Castillo & Tercero & \\
\hline Dn Juan de Cañaveras & \multicolumn{2}{|l}{} \\
\hline
\end{tabular}

\section{REFERENCIAS BIBLIOGRÁFICAS}

Álvarez-Coca GonzÁlez, María Jesús. «El Consejo de órdenes Militares». Cuadernos de Historia Moderna, 1994, 15, pp. 297-323.

AndúJar Castillo, Francisco. Consejo y consejeros de Guerra en el siglo XVIII. Granada: Universidad de Granada, 1996.

ARIAS DE SAavedra Alias, Inmaculada. "Los fiscales de la Audiencia de Sevilla en el siglo XVIII: notas para su historia». Cuadernos de Historia Moderna, 2011, 36, pp. 129-150.

CABRera BosCh, María Isabel. El consejo real de Castilla y la ley. Madrid: CSIC, 1993.

CARABIAS TORRES, Ana María. ¿La muerte del letrado? Consideraciones sobre la tipología del oficial español en el siglo XVIII. En Dios DE Dios, Salustiano de y ToRIJANo, Eugenia (coords.). Cultura política y práctica del derecho. Juristas de Salamanca, siglos XV-XX. Salamanca: Ediciones Universidad de Salamanca, 2012, pp. 143-238.

Castellano Castellano, Juan Luis. Gobierno y poder en la España del siglo XVIII. Granada: Universidad de Granada, 2006.

Castro, Concepción de. A la sombra de Felipe V. José Grimaldo, ministro responsable (17031726). Madrid: Marcial Pons, 2004.

Coronas González, Santos Manuel. Ilustración y Derecho. Los fiscales del Consejo de Castilla en el siglo XVIII. Madrid: Ministerio Administraciones Públicas, 1992.

DeDieu, Jean Pierre. «La Nueva Planta en su contexto. Las reformas del aparato del Estado en el reinado de Felipe V». Manuscrits, 2000, 18, pp. 113-139.

Dedieu, Jean Pierre. "Dinastía y élites de poder en el reinado de Felipe V». En Fernández Albaladejo, Pablo (ed.). Los Borbones. Dinastía y memoria de nación en la España del siglo XVIII. Madrid: Marcial Pons, 2002, pp. 381-399. 
Dedieu, Jean Pierre. "La muerte del letrado». En Aranda Pérez, José Francisco (Coord). Letrados, juristas y burócratas en la España Moderna. Cuenca: Universidad de Castilla-La Mancha, 2005, pp. 479-511.

Dedieu, Jean Pierre. "El aparato de gobierno de la monarquía española en el siglo XVIII». En PÉREZ SARRIÓN, Guillermo (Coord). Más Estado y más mercado: absolutismo y economía en la España del siglo XVIII. Madrid: Sílex, 2011, pp. 53-74.

Delgado Barrado, José Miguel. Aquiles y Teseos. Bosquejos del reformismo borbónico. Granada: Universidad de Granada, 2007.

Domínguez Ortiz, Antonio. Sociedad y Estado en el siglo XVIII español. Barcelona: Ariel, 1976.

DuBET, Anne. «¿a importación de un modelo francés? Acerca de algunas reformas de la administración española a principios del siglo XVIII». Revista de Historia Moderna, 2007, 25, pp. 207-233.

DuBET, Anne. Un estadista francés en la España de los Borbones: Juan Orry y las primeras reformas de Felipe V (1701-1706). Madrid: Biblioteca Nueva, 2008.

DuBET, Anne. "Comprender las reformas de Hacienda a principios del siglo XVIII. La buena administración según el marqués de Campoflorido». HMiC: història moderna i contemporània. 2012, 10, pp. 20-52.

DuBET, Anne y Ruíz IBÁÑEZ, José Javier. Las monarquías española y francesa (siglos XVIXVIII). ¿Dos modelos políticos? Madrid: Casa de Velázquez, 2010.

EGIDO López, Teófanes. Las reformas fracasadas. El significado de Macanaz. En Pérez VIllanueva, Joaquín y Escandell Bonet, Bartolomé (dirs.). Historia de la Inquisición en España y América (vol. I.). Madrid: B. A. C., 1984, pp. 1234-1247.

EGIDO LóPEz, Teófanes. Opinión pública y oposición al poder en la España del siglo XVIII (1713-1759). Valladolid: Fundación española de Historia Moderna, 2002.

Escudero López, José Antonio. Los secretarios de Estado y del Despacho, 1474-1724 (vol. III). Madrid: Instituto de Estudios Administrativos, 1979.

ESCUDERO LÓPEZ, José Antonio. "La reconstrucción de la administración central en el siglo XVIII». En VV. AA. La época de los primeros Borbones (XXIX/I). Madrid: Espasa-Calpe, 1987, pp. 79-175.

FAYARD, Janine. "La tentative de rêforme du Conseil de Castille sous le regne de Philippe V (1713-1715)». Mélanges de la Casa de Velázquez, 1966, 2, pp. 259-282.

FAYARD, Janine. "Los ministros del consejo real de Castilla». Hidalguía, 1981, 165, p. 191.

FAYARD, Janine. Los miembros del Consejo de Castilla (1621-1746). Madrid: Siglo XXI, 1982.

Fernández Albaladejo, Pablo. Fragmentos de monarquía: Trabajos de Historia politica. Madrid: Alianza, 1992, pp. 353-454.

Francisco Olmos, José María de. Los miembros del Consejo de Hacienda (1722-1838) y Organismos económico-monetarios. Madrid: Castellum, 1997.

García-BAdells ARIas, Luis María. "Felipe V, la Nobleza Española y el Consejo de Castilla. La Explicación jurídica e histórica de la consulta que hizo el Real Consejo de Castilla, atribuida a Macanaz». Cuadernos de Historia del Derecho, 2005, 12, pp. 125-149.

GarCía FuERTES, Gemma. "Francesc Ametller i Perer (1657/8-1726). Un jurista català al servei de Felip V». Pedralbes: revista d'Història moderna, 2008, 28/1, pp. 165-202.

García-Hevia, José María. «Macanaz y su propuesta de reforma del Santo. Oficio de 1714». Revista de Inquisición, 1996, 5, pp. 218-327.

GIL Pujol, Xavier. «Notas sobre el estudio del poder como nueva valoración de la historia política». Pedralbes: Revista d'Historia Moderna, 1983, 3, pp. 61-88. 
GÓMEZ GONZÁLEZ, Inés. «Más allá de la colegialidad: una aproximación al juez de comisión en la España del Antiguo Régimen". Chronica Nova. Revista de Historia Moderna de la Universidad de Granada, 2011, n. ${ }^{\circ}$ 37, pp. 21-40.

GUERRERO ELECALDE, Rafael. Las élites vascas en el gobierno de la monarquía borbónica: redes sociales, carreras y hegemonía en el siglo XVIII (1700-1746). Tesis Doctoral, Universidad del País Vasco, 2012.

Hernández Franco, Juan y Precioso IzQuierdo, Francisco. "Discursos enfrentados en los albores de la Monarquía borbónica. Reacciones al Pedimento Fiscal de Macanaz». Mediterranea-ricerche storiche, 2014, n. ${ }^{\circ}$ 30, pp. 77-82.

Imízcoz BeunZA, José María y Guerrero ElECALDE, Rafael. «Familias en la Monarquía. La política familiar de las elites vascas y navarras en el imperio de los Borbones». En ImízCOZ Beunza, José María (ed.). Casa, familia y sociedad (País Vasco, España y América, siglos XV-XIX). Bilbao: Universidad del País Vasco, 2004, pp. 178-179.

KAmen, Henry. La Guerra de Sucesión. Barcelona: Grijalbo, 1974.

KAMEN, Henry. Felipe V. El rey que reinó dos veces. Madrid: Temas de hoy, 2010.

LóPEZ-CoRdón CORTEZO, María Victoria. «Instauración dinástica y reformismo administrativo: la implantación del sistema ministerial». Manuscrits, 2000, 18, pp. 93-111.

LóPEz-Cordón CORTEzo, María Victoria. "La Nueva Planta del Estado: consejos y secretarías». En Morales Moya, Antonio (ed.). 1714. Cataluña en la España del siglo XVIII. Madrid:Cátedra, 2014, pp. 113-156.

Martín Gaite, Carmen. Macanaz, otro paciente de la Inquisición. Barcelona: Destino Libro, 1982.

Martín Marcos, David. El papado y la Guerra de Sucesión española. Madrid: Marcial Pons, 2011.

MARTínez Millán, José. «Las investigaciones sobre patronazgo y clientelismo en la Administración de la Monarquía Hispana durante la Edad Moderna». Studia Historica. Historia Moderna, 1996, 15, pp. 89-97.

MARTíNEZ RIPOLL, Antonio. «Regalismo borbónico, reformismo eclesiástico y relaciones con Roma: el cardenal Belluga». En COnTreras, Jaime; Alvar, Alfredo y Ruíz, José Ignacio. Política y cultura en la época moderna: Cambios dinásticos, milenarismos, mesianismos y utopías. Madrid: Universidad de Alcalá, 2004, pp. 29-50.

Molas Ribalta, Pere. La Audiencia borbónica del reino de Valencia (1707-1834). Alicante: Universidad de Alicante, 1999.

Molas Ribalta, Pere. "Aragón en el Consejo de Castilla». Cuadernos Dieciochistas, 2001, 2, pp. 13-35.

Molas Ribalta, Pere. Los gobernantes de la España Moderna. Madrid: Actas, 2008.

MoYa PINEDO, Jesús. Corregidores y regidores de Cuenca, siglos XV al XIX. Cuenca, 1977.

PÉREZ SAMPER, María de los Ángeles. "La Audiencia de Cataluña en el siglo XVIII». Revista de historia moderna: Anales de la Universidad de Alicante, 1995, 13-14, pp. 51-71.

SAlas Balust, Luis. "Reales reformas de los antiguos Colegios de Salamanca anteriores a las del reinado de Carlos III (1628-1770)». Estudios y Documentos, 1956, 10, pp. 45-62.

Trailonte Díez, José Antonio. «Señorío de Baños». Publicaciones de la Institución Tello Téllez de Meneses, 1996, 67, pp. 169-180.

Troyano Chicharro, José Manuel. "La casa de la Cueva en el Bedmar del s. XVIII". Sumuntán, 2001, 14, pp. 63-74.

VIDAL, José Juan. «El Reino de Mallorca del filipismo al austracismo, 1700-1715». En SERRANO Martín, Eliseo (ed.). Felipe Vy su tiempo (vol. II). Zaragoza: Instituto Fernando el Católico, 2004, pp. 151-210. 